\title{
Suppression of the Secretion of Thyroid Stimulat- ing Hormone by Endogenous Triiodothyronine and Thyroxine: an Observation on a Patient of Chronic Thyroiditis Treated with Corticosteroid
}

\author{
Toshiro Sakurada, Shintaro SaIto, Makiko Yamamoto, \\ Toru Yamaguchi, Katsumi Yoshida, Masamichi Ohtaki, \\ Ryuji Shioji and KaOru Yoshinaga \\ Department of Internal Medicine, Tohoku University School \\ of Medicine, Sendai
}

Sakurada, T., Satto, S., Yamamoto, M., Yamaguchi, T., Yoshida, K., Ohtaki, M., Shioj, R. and Yoshinaga, K. Suppression of the Secretion of Thyroid Stimulating Hormone by Endogenous Trïodothyronine and Thyroxine: an Observation on a Patient of Chronic Thyroiditis Treated with Corticosteroid. Tohoku J. exp. Med., 1974, 112 (4), 361-364_Administration of prednisolone, $30 \mathrm{mg}$ per day, for a month followed by its alternate-day administration was very effective to restore the thyroid function and clinical symptoms in a rare case of hypothyroidism caused by chronic thyroiditis with inflammatory symptoms. Decreased serum $\mathrm{T}_{3}$ and $\mathrm{T}_{4}$ in this patient were increased to normal values by the administration of prednisolone and increased serum TSH became undetectable. __. triiodothyronine; chronic thyroiditis; hypothyroidism; thyroid stimulat-

ing hormone

Effect of prednisolone on the concentration of serum triiodothyronine $\left(\mathrm{T}_{3}\right)$, thyroxine $\left(\mathrm{T}_{4}\right)$ and thyroid stimulating hormone (TSH) in a patient of hypothyroidism caused by chronic thyroiditis with inflammatory symptoms is presented in this paper and the relationship among endogenous serum $\mathrm{T}_{3}, \mathrm{~T}_{\mathbf{4}}$ and TSH is discussed.

Case report: A 43-year-old house wife. In October 1964, she had a fever of $39^{\circ} \mathrm{C}$, sore throat and goiter. Three months later these symptoms subsided. In June 1971, she noticed the same symptoms again and was admitted to our hospital in November 1971.

On admission her pulse rate was $66 /$ min, regular. Her voice was hoarse, the face was slightly puffy and skin was dry. Eye signs were not remarkable. The thyroid gland was enlarged (estimated weight $87 \mathrm{~g}$ ), elastic and soft, and its upper poles were nodular. The Achilles tendon reflex was retarded.

The erythrocyte sedimentation rate was $134 \mathrm{~mm}$ per $\mathrm{hr}$. Serum total protein was $8.8 \mathrm{~g} / 100 \mathrm{ml}$, of which $38.8 \%$ was $\gamma$-globulin. Serum total cholesterol was $226 \mathrm{mg} / 100 \mathrm{ml}$. Rheumatoid arthritis test was positive, C-reactive protein test was three plus and antistreptolysin $O$ test was 50 Todd units.

Basal metabolic rate (BMR) was $-15 \%$. Resin-sponge ${ }^{131} \mathrm{I}_{-} \mathrm{T}_{3}$ uptake (Abbott

Received for publication, February 16, 1974. 
Co.) was $21 \%$. Serum $\mathrm{T}_{4}$ and $\mathrm{T}_{3}$, measured by radioimmunoassay (Sakurada et al. 1973a; Yamaguchi et al. 1973) were $1.2 \mu \mathrm{g} / 100 \mathrm{ml}$ and $11 \mathrm{ng} / 100 \mathrm{ml}$, respectively. The thyroidal 24-hr uptake of ${ }^{131}$ I ( ${ }^{131} \mathrm{I}$-uptake) was $4 \%$ and failed to increase after daily intramuscular injection of 10 U.S.P. of TSH for three days (TSHtest). The tanned-red-cell hemagglutination test (TRC) was 1:2,500,000. Serum TSH measured by double-antibody radioimmunoassay (normal range: below $8 \mu \mathrm{U} /$ ml) was $330 \mu \mathrm{U} / \mathrm{ml}$.

Histological findings of the thyroid gland (Fig. 1) obtained by open biopsy were large and oxyphilic epithelial cells, small follicles, fibrous tissue proliferation, diffuse infiltration of small round cells and lymphoid follicle formation. These changes indicated chronic thyroiditis.

Therefore the present case was diagnosed as hypothyroidism caused by chronic thyroiditis with inflammatory symptoms.

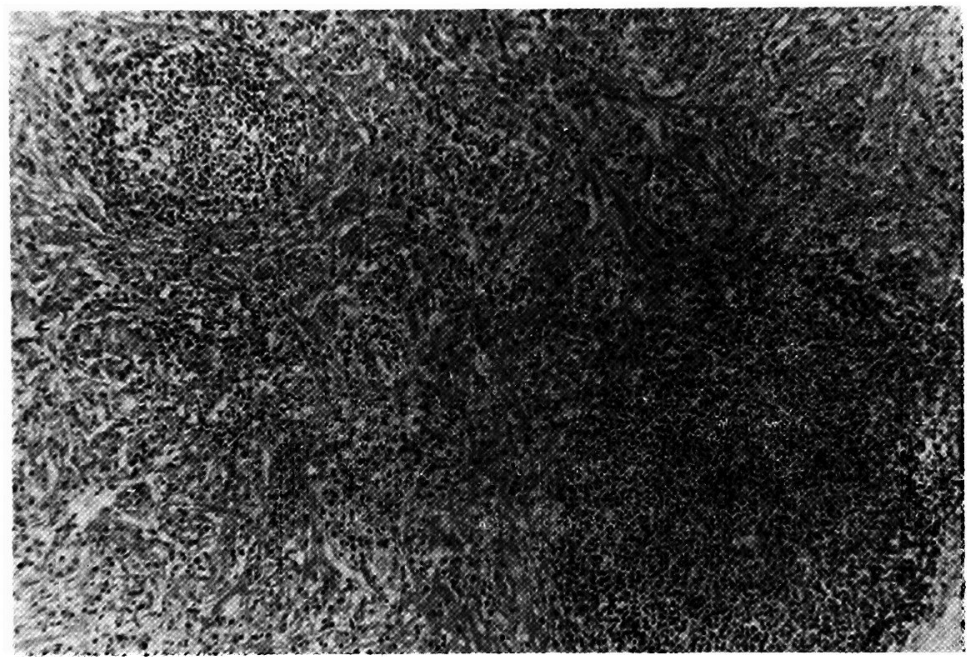

Fig. 1. Histological feature of thyroid gland of the present case.

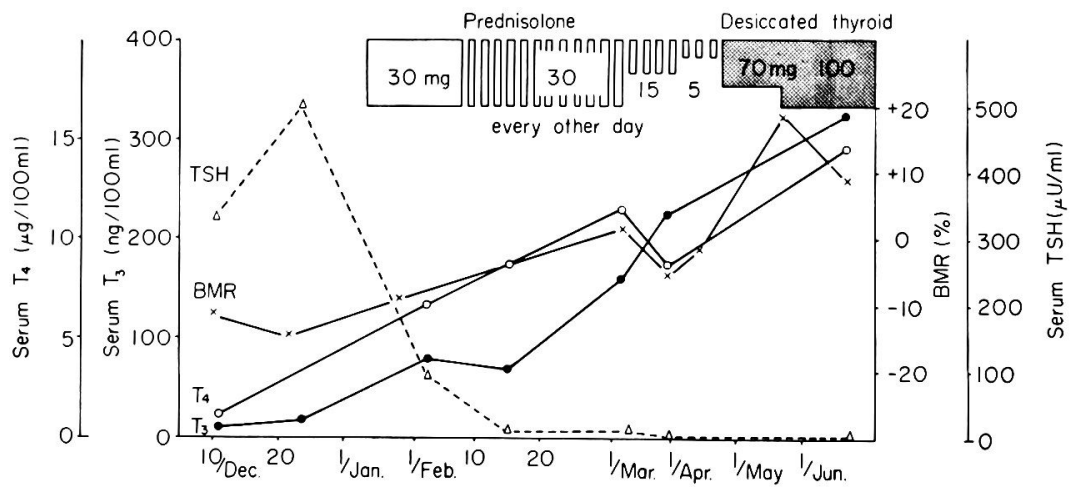

Fig. 2. Changes of the levels of serum $\mathrm{T}_{4}, \mathrm{~T}_{3}$ and TSH in the present case during the administration of prednisolone. 
She was treated with $30 \mathrm{mg}$ of prednisolone per day for 30 days, thereafter the same dose of prednisolone was administered every other day (Fig. 2). A month after the start of administration of prednisolone, she became symptom free. ${ }^{131}$ I-uptake was restored to $39 \%$. And BMR, resin-sponge ${ }^{131} \mathrm{I}$-uptake, and serum $\mathrm{T}_{4}$ and $\mathrm{T}_{3}$ values were increased to normal: $-9.5 \%, 31 \%, 6.7 \mu \mathrm{g} / 100 \mathrm{ml}$ and $80 \mathrm{ng} / 100 \mathrm{ml}$, respectively. At that time, serum $\mathrm{TSH}$ value was decreased to $90 \mu \mathrm{U} / \mathrm{ml}$ and its value became undetectable when serum $\mathrm{T}_{4}$ and $\mathrm{T}_{3}$ values became $11 \mu \mathrm{g} / 100 \mathrm{ml}$ and $87 \mathrm{ng} / 100 \mathrm{ml}$, respectively. About three months later, prednisolone was discontinued and desiccated thyroid was given without any aggravation of clinical symptoms for the following two years till now.

\section{Discussion}

There were few cases of hypothyroidism caused by chronic thyroiditis with inflammatory symptoms (Doniach and Hudson 1960). As the inflammatory symptoms in chronic thyroiditis are similar to those in subacute thyroiditis, immunological and histological studies are necessary to differentiate them. In the present case, titer of TRC was 1:2,500,000 and histological features of the thyroid gland showed chronic thyroiditis.

When steroid was given to the patient of hypothyroidism caused by chronic thyroiditis, it was reported that there was a marked fall in the antibody titers simultaneously with restoration of the thyroid function and disappearance of goiter (Berglund et al. 1960). Steroid has two actions (Berglund et al. 1960): inhibition of the production of antibodies and non-specific anti-inflammatory effect on the goiter; but the titer of TRC in the present case did not decrease though the size of the goiter became smaller after the administration of prednisolone.

During the treatment with prednisolone (Fig. 2), all decreased values of 131Iuptake, serum $\mathrm{T}_{3}$ and $\mathrm{T}_{4}$ in the present case became normal ones and serum TSH value became undetectable as her clinical condition was restored. It is well known that TSH secretion is accelerated by feedback control between serum $\mathrm{T}_{4}$ and TSH in hypothyroid patients (Hall et al. 1971). And exogenous $\mathrm{T}_{3}$ and $\mathrm{T}_{4}$ are reported to be able to suppress the secretion of serum TSH in hypothyroid patients (Cotton et al. 1971). But it has never been reported that the endogenous $T_{3}$ and $T_{4}$, increased by the administration of steroid, suppressed the secretion of serum TSH by feedback control.

It is very interesting from pathophysiological point of view that thyroid hormones were restored to normal by the administration of prednisolone though almost all follicles were destroyed as shown in Fig. 1.

We have observed that in normal subjects serum $T_{3}$ was more rapidly secreted from thyroid gland than $\mathrm{T}_{4}$ when it was stimulated by exogenous TSH (Sakurada et al. 1973b). As shown in Fig. 2, serum $\mathrm{T}_{3}$ value in the present case became constant more rapidly than serum $\mathrm{T}_{4}$ value by the administration of prednisolone.

When the steroid therapy is instituted to repress the inflammatory symptomes of chronic thyroiditis, prolonged administration of it is inevitable to maintain the 
effect, resulting in distressing side-actions. In the present case, $30 \mathrm{mg}$ of prednisolone was given for a month, and then 30,15 and $5 \mathrm{mg}$ of it were administered every other day. By this method of alternate-day corticosteroid therapy (Ackerman and Nolan 1968), all inflammatory symptoms of the present case diminished without inducing any side-action. Even after the steroid was switched to the desiccated thyroid, she remains symptom free for two years. The therapeutic trial described here is presented as an effective one in the treatment of chronic thyroiditis with inflammatory symptoms which has been thought to be difficult to be treated.

\section{References}

1) Ackerman, G.L. \& Nolan, C.M. (1968) Adrenocortical responsiveness after alternateday corticosteroid therapy. New Engl. J. Med., 278, 405-409.

2) Berglund, G., Broberger, O. \& Zetterström, R. (1960) Hashimoto's disease in childhood. A clinical and immunological study of five cases. Acta paediat., 49, 663-673.

3) Cotton, G.E., Gorman, C.A. \& Mayberry, W.E. (1971) Suppression of thyrotropin (h-TSH) in serums of patients with myxedema of varying etiology treated with thyroid hormones. New Engl. J. Med., 285, 529-533.

4) Doniach, D. \& Hudson, R.V. (1960) Human auto-immune thyroiditis: clinical studies. Brit. med. J., 1, 365-373.

5) Hall, R., Amos, J. \& Ormston, B.J. (1971) Radioimmunoassay of human serum thyrotrophin. Brit. med. J., 1, 582-585.

6) Sakurada, T., Saito, S., Yamaguchi, T., Yamamoto, M., Demura, R., Demura, H., Fukuchi, S., Yoshida, K. \& Torikai, T. (1973 a) Radioimmunoassay of triiodothyronine. Tohoku J. exp. Med., 110, 329-340.

7) Sakurada, T., Yamaguchi, T., Yoshida, K., Yamamoto, M., Demura, R. \& Saito, S. $(1973 \mathrm{~b})$ Inorganic iodide therapy of triiodothyronine-thyrotoxicosis. Tohoku $J$. exp. Med., 111, 219-227.

8) Yamaguchi, T., Sakurada, T., Yoshida, K., Yamamoto, M., Saito, S. \& Fukuchi, S. (1973) Radioimmunoassay of thyroxine. Folia Endocr. jap. (Jap.), 49, 301 (abstract). 